\title{
Urgences
}

\section{il n'y avait pas...}

\section{Céline Bouchard}

Numéro 15, octobre 1986

\section{Épigraphiques}

URI : https://id.erudit.org/iderudit/025284ar

DOI : https://doi.org/10.7202/025284ar

Aller au sommaire du numéro

\section{Éditeur(s)}

Urgences

\section{ISSN}

0226-9554 (imprimé)

1927-3924 (numérique)

Découvrir la revue

Citer ce document

Bouchard, C. (1986). il n'y avait pas... Urgences, (15), 16-17.

https://doi.org/10.7202/025284ar

Ce document est protégé par la loi sur le droit d'auteur. L'utilisation des services d'Érudit (y compris la reproduction) est assujettie à sa politique d'utilisation que vous pouvez consulter en ligne.

https://apropos.erudit.org/fr/usagers/politique-dutilisation/
Cet article est diffusé et préservé par Érudit.

Érudit est un consortium interuniversitaire sans but lucratif composé de l'Université de Montréal, l'Université Laval et l'Université du Québec à Montréal. Il a pour mission la promotion et la valorisation de la recherche. https://www.erudit.org/fr/ 


\section{Céline Bouchard}

L'univers s'exprimera lui-même dans l'exacte mesure où quelqu'un pourra dire: "Je lis, donc ça écrit."

Italo Calvino: Si par une nuit d'hiver un voyageur

il n'y avait pas de réponse précise, sans doute le problème n'avait pas été posé correctement, mais les mots - comme le mot sublime - ne décrivaient pas l'objet exposé.

elle regardait par-delà les apparences, l'objet enfoui dans un miroir de brume qui s'élevait du sable chaud et qui dissimulait le soleil en cette fin d'après-midi, alors que l'ombre de l'île projetée dans cette grisaille prenait des proportions démesurées.

il n'y avait qu'une route menant vers le brouillard, puis elle voulut dire exactement ce qu'elle voyait, mais surtout ce qu'elle ressentait: "en cet instant la brume m'attire irrésistiblement vers cette vision si belle, la présence de cette île, et je ne sais que des mots divers - comme le mot infini - elle apprenait à devenir plus attentive à tout ce qui s'unissait dans une juste mesure.

elle évoquait bien des mots pour dire l'objet exposé, mais les mots lus de l'amour fou que quelqu'un avait écrit, pouvait-elle les utiliser?

il n'était pas question d'établir un lien précis entre l'objet dit et le sujet lu, alors elle choisit de reprendre en sa mémoire les mots - comme le mot oubli - résultant de cette image absolue, pour mieux saisir ce que représentait ce miroir.

elle se tenait debout - c'était la nuit - devant la mer sans vague; elle observait une ligne de sable sans eau, à l'extrême limite du sable humide, la ligne que la mer emportait en se retirant vers le gris de l'eau et du ciel confondus.

il ne pouvait qu'en être ainsi; elle savait la présence d'une lune par-delà les nuages, mais elle n'arrivait pas à dire le sublime, l'infini et l'oubli, puis elle découvrit que son voyage reflétait encore de multiples mots non dits.

elle avait écrit: "parfois les mots en disent beaucoup trop, mais aussi parfois il arrive qu'on manque de mots pour exprimer le temps d'avant et l'espace devant". 